\title{
A microbiology-based multi-parametric approach towards assessing biological stability in drinking water distribution networks
}

\author{
Karin Lautenschlager ${ }^{a, b}$, Chiachi Hwang ${ }^{c}$, Wen-Tso Liu ${ }^{c}$, Nico Boon ${ }^{d}$, Oliver Köster ${ }^{e}$, \\ Hans Vrouwenvelder ${ }^{f, g}$, Thomas Egli ${ }^{a, b}$, Frederik Hammes ${ }^{a, *}$ \\ ${ }^{a}$ Eawag, Swiss Federal Institute for Aquatic Science and Technology, Überlandstr. 133, CH-8600 Dübendorf, Switzerland \\ ${ }^{\mathrm{b}}$ ETH Zürich, Institute of Biogeochemistry and Pollutant Dynamics, CH-8092 Zürich, Switzerland \\ ${ }^{c}$ Department of Civil and Environmental Engineering, University of Illinois Urbana-Champaign, Urbana, IL 61801, USA \\ ${ }^{d}$ Ghent University, Faculty of Bioscience Engineering, Laboratory of Microbial Ecology and Technology (LabMET), Gent, Belgium \\ e Zürich Water Supply (WVZ), Hardhof 9, P.O. Box 1179, CH-8021 Zürich, Switzerland \\ ${ }^{\mathrm{f}}$ King Abdullah University of Science and Technology, Water Desalination and Reuse Center, Thuwal, Saudi Arabia \\ ${ }^{g}$ Delft University of Technology, Department of Biotechnology, Environmental Biotechnology Group, Julianalaan 67, 2628 BC Delft, The \\ Netherlands
}

\section{A R T I C L E I N F O}

Article history:

Received 5 November 2012

Received in revised form

23 February 2013

Accepted 3 March 2013

Available online 15 March 2013

\section{Keywords:}

Biological stability

Flow cytometry

Microbial community composition

Pyrosequencing

\section{A B S T R A C T}

Biological stability of drinking water implies that the concentration of bacterial cells and composition of the microbial community should not change during distribution. In this study, we used a multi-parametric approach that encompasses different aspects of microbial water quality including microbial growth potential, microbial abundance, and microbial community composition, to monitor biological stability in drinking water of the non-chlorinated distribution system of Zürich. Drinking water was collected directly after treatment from the reservoir and in the network at several locations with varied average hydraulic retention times $(6-52 \mathrm{~h})$ over a period of four months, with a single repetition two years later. Total cell concentrations (TCC) measured with flow cytometry remained remarkably stable at $9.5( \pm 0.6) \times 10^{4}$ cells $/ \mathrm{ml}$ from water in the reservoir throughout most of the distribution network, and during the whole time period. Conventional microbial methods like heterotrophic plate counts, the concentration of adenosine tri-phosphate, total organic carbon and assimilable organic carbon remained also constant. Samples taken two years apart showed more than $80 \%$ similarity for the microbial communities analysed with denaturing gradient gel electrophoresis and 454 pyrosequencing. Only the two sampling locations with the longest water retention times were the exceptions and, so far for unknown reasons, recorded a slight but significantly higher TCC $\left(1.3( \pm 0.1) \times 10^{5}\right.$ cells $\left./ \mathrm{ml}\right)$ compared to the other locations. This small change in microbial abundance detected by flow cytometry was also clearly observed in a shift in the microbial community profiles to a higher abundance of members from the Comamonadaceae ( $60 \%$ vs. $2 \%$ at other locations). Conventional microbial detection methods were not able to detect changes as observed with flow cytometric cell counts and microbial community analysis.

\footnotetext{
Abbreviations: ATP, adenosine tri-phosphate; AOC, assimilable organic carbon; BDOC, biodegradable organic carbon; CFU, colony forming units; DGGE, denaturing gradient gel electrophoresis; FCM, flow cytometry; HPC, heterotrophic plate counts; OTU, operational taxonomic units; TOC, total organic carbon.

* Corresponding author. Tel.: +41 44823 5350; fax: +41 448235547.

E-mail address: frederik.hammes@eawag.ch (F. Hammes).
}

0043-1354/\$ - see front matter @ 2013 Elsevier Ltd. All rights reserved.

http://dx.doi.org/10.1016/j.watres.2013.03.002 
Our findings demonstrate that the multi-parametric approach used provides a powerful and sensitive tool to assess and evaluate biological stability and microbial processes in drinking water distribution systems.

(c) 2013 Elsevier Ltd. All rights reserved.

\section{Introduction}

The WHO drinking water guideline states: "Water entering the distribution system must be microbiologically safe and ideally should also be biologically stable" (WHO, 2006). Water treatment systems normally have source water protection and multiple barriers for pathogens to ensure that microbiological safety requirements are met (WHO, 2006). However, the "biological stability" requirement is considerably less defined, both in terms of what it actually means and how it can be achieved. Intuitively, biological stability would imply no changes occurring in the concentrations and composition of the microbial community in the water during distribution. In many countries a disinfectant residual (e.g., monochloramine) is maintained in the distribution network to inhibit microbial growth and thus enforce stability (LeChevallier et al., 1993; WHO, 2006). Alternatively, in some European countries such as Switzerland, The Netherlands, Austria, and Germany, biological stability is achieved through limitation of growth supporting nutrients in water (Hambsch, 1999; Hammes et al., 2010a; Van der Kooij et al., 1999).

Appropriate methods are needed to monitor biological stability in drinking water systems. A conventional but indirect approach to measure biological stability is assessing the microbial growth potential of a water sample, using assimilable organic carbon (AOC) measurements, biodegradable dissolved organic carbon (BDOC), and pathogen growth potential (PGP) assays (Escobar and Randall, 2001; Hammes and Egli, 2005; Laurent et al., 2005a; Van der Kooij, 2000; Vital et al., 2010). These parameters have in some cases been related to the degree of growth or contamination observed in drinking water distribution systems and some guideline values for "biologically stable" water have been suggested for AOC in the absence of disinfectants ( $<10 \mu \mathrm{g} / \mathrm{l}$; Van der Kooij, 2000) as well as in the presence of disinfectants $(<100 \mu \mathrm{g} / \mathrm{l}$; LeChevallier et al., 1993). While certainly useful, these growth potential tests are all predictive. During drinking water distribution, multiple factors such as pipe materials, flow velocity, temperature shifts, mixing zones and stagnation zones, sediments, biofilms, or in the worst-case scenario, intrusion of untreated water from the subsurface, can influence the biological stability of the water (Laurent et al., 2005b, 2005c; WHO, 2006). None of the above mentioned conventional growth potential methods are capable to detect or predict the impact of such factors accurately on their own.

A more direct and complimentary approach is to collect water from different locations in a drinking water distribution network and to compare the microbial quality of such water samples directly with each other using appropriate methodologies. However, as used here, the term "appropriate methodologies" is potentially problematic, as water utilities and even researchers often do not look beyond the conventional cultivation-based heterotrophic plate count (HPC) method (Van der Kooij et al., 2003). Van der Kooij $(2000,2003)$ previously stressed the value of a broader multi-parametric approach, and suggested to include alternative/advanced detection methods such as adenosine tri-phosphate (ATP) and molecular tools. However, until now only a few studies addressed biological stability from actual network samples using direct methods such as total cell counts enumeration via microscopy, or flow cytometry (FCM), or measurement of ATP concentrations (Hammes et al., 2010a; Laurent et al., 2005c; van der Wielen and Van der Kooij, 2010; Vital et al., 2012). Moreover, cultivation-independent microbial community analysis has to our knowledge never been used specifically as a tool to assess biological stability in non-chlorinated drinking water distribution networks. In fact, most information on the indigenous microbial community composition in drinking water is limited to chlorinated drinking water (e.g., Burtscher et al., 2009; Eichler et al., 2006; Henne et al., 2012a, 2012b; Hong et al., 2010; Revetta et al., 2010; Roeder et al., 2010; Pinto et al., 2012).

In the present study, treated drinking water from seven locations with increasing average hydraulic retention times (0-52 h) within the distribution network of Zürich (CH) was sampled. Samples were taken monthly during four months and again two years later to assess the long-term biological stability of the drinking water in the distribution system. We used a multi-parametric approach to monitor biological stability, including selected parameters of water chemistry, microbial abundance, microbial growth potential, and characterization of microbial communities. This enabled a direct assessment of quantitative and qualitative changes in water quality, and provided a way to detect and characterize stability and instability during drinking water distribution.

\section{Materials and methods}

\subsection{Sampling}

Water was sampled from the full-scale distribution network of Zürich $(\mathrm{CH})$ receiving non-chlorinated drinking water from a multi-step drinking water treatment facility (for details, see Hammes et al., 2010a). In this facility the water is treated through sequential ozonation and biofiltration steps before the water is collected in the main reservoir of the plant (Hammes et al., 2010a) before distribution of the drinking water. The reservoir and six points of the connected distribution network, containing water with increasing hydraulic retention times (ca. 6-52 h), were sampled six times in the time period from November 2008 until February 2009 and once in September 2010 (Fig. 1). Only sampling points that were guaranteed to receive water samples from the main treatment 


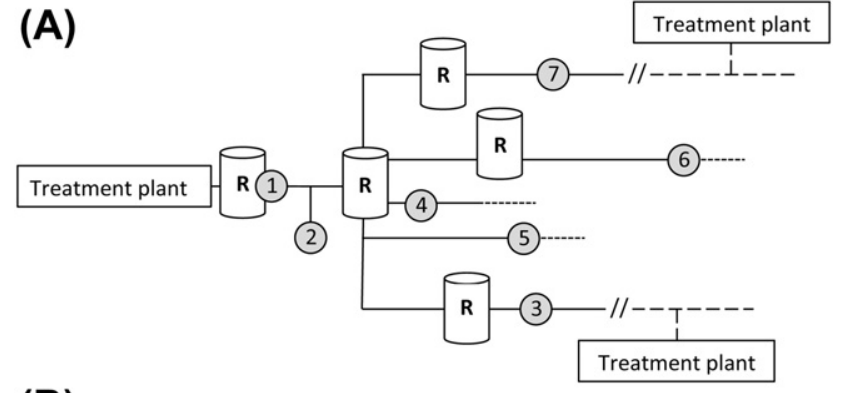

(B)

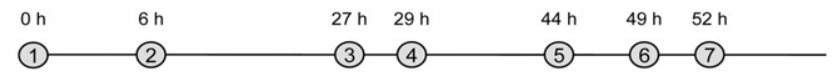

Fig. 1 - Scheme of the estimated water flow in the drinking water network of Zürich. Water from several treatment plants enters the system and water is collected in several reservoirs (R) before it is distributed. The sampling locations of this study, numbered by increasing residence times, are indicated by the grey circles (A). The estimated average water retention time at each sampling point was calculated and is indicated in a simplified scheme (B).

plant were selected (Fig. 1). The average water retention time at each sampling point was calculated by the local water utility, but is subject to variations due to daily usage. To minimise the impact of these variations, water samples were always collected on the same weekday and same time. Water samples from the network were collected from public fountains with continuously flowing water using sterile and carbon-free Schott bottles (2 l). An additional sample of $500 \mathrm{ml}$ was taken for the analysis of water chemistry (Table 1). The temperature was measured directly at each sampling location. All samples were processed on the day of sampling. Samples for DGGE and pyrosequencing were filtered (2 l) using cleaned and sterilised filter units (Nalgene, Thermo-Scientific) with sterile $0.22 \mu \mathrm{m}$ filters and the filters were stored at $-20^{\circ} \mathrm{C}$ until further analysis.

\subsection{Adenosine tri-phosphate (ATP) analysis}

Total ATP was determined using the BacTiter-Glo ${ }^{\text {TM }}$ reagent (Promega Corporation, Madison, WI, USA) as described elsewhere (Hammes et al., 2010b). A water sample (500 $\mu$ l) and ATP reagent $(50 \mu \mathrm{l})$ were warmed $(1 \mathrm{~min})$ to $38{ }^{\circ} \mathrm{C}$ simultaneously in separate sterile Eppendorf tubes. The sample and the reagent were then combined and the luminescence was measured after $20 \mathrm{~s}$ reaction time at $38^{\circ} \mathrm{C}$. The data were collected as relative light units (RLU) and converted to ATP (nM) by means of a calibration curve made with a known ATP standard (Promega). Free ATP was measured by first filtering each sample through a $0.1 \mu \mathrm{m}$ pore size sterile syringe filter (Millex ${ }^{\circledR}-G P$, Millipore), and then using the filtrate to repeat the analysis described above. ATP was measured in triplicate for all samples, and the standard deviation of the measurement was always below $4 \%$.

\subsection{Intact and total cell counts}

Flow cytometric analysis of the total and intact cell concentrations was done as described in Berney et al. (2008). Briefly, microbial cells were stained with a $10 \mu \mathrm{l} / \mathrm{ml}$ working solution of propidium iodide (PI) in combination with $\mathrm{SYBR}^{\circledR}$ Green I (SG/PI) to measure membrane-intact cells. Working solutions of the dyes were prepared as follows: SYBR ${ }^{\circledR}$ Green I was diluted 100-fold in anhydrous dimethylsulfoxide (DMSO) and mixed with PI (0.6 mM final concentration). Samples were then incubated in the dark for at least 15 min before measurement. Samples were diluted 10-fold just before measurement in filtered $\left(0.1 \mu \mathrm{m}\right.$; Millex ${ }^{\circledR}$-GP, Millipore), bottled mineral water (EVIAN, France). The concentration measured with the flow cytometer was always less than $2 \times 10^{5}$ cells $/ \mathrm{ml}$. Flow cytometry was performed by using a portable CyFlow SL flow cytometer (Partec, Münster, Germany) equipped with a $20 \mathrm{~mW}$ solid state laser, emitting at a fixed wavelength of $488 \mathrm{~nm}$, and volumetric counting hardware.

\subsection{Heterotrophic plate counts (HPC)}

The HPC method was performed with R2 agar (R2A) since it was observed previously that R2A resulted in higher colony counts than conventional plate count agar (PCA), which is recommended in the Swiss guidelines for drinking water (Uhl and Schaule, 2004; SLMB, 2000, 56, E.1). In short, $1 \mathrm{ml}$ of the water sample was transferred to a sterile Petri dish and mixed with about $15 \mathrm{ml}$ warm R2A, (Oxoid, Cambridge, UK). The agar was kept at $42{ }^{\circ} \mathrm{C}$ before use. The plates were

Table 1 - Chemical water quality parameters measured in the drinking water network. Average values and standard deviations from six measurements are indicated for each sampling point (see also Fig. 1).

\begin{tabular}{|c|c|c|c|c|c|c|c|}
\hline $\begin{array}{l}\text { Sampling } \\
\text { location }\end{array}$ & $\begin{array}{l}\text { Retention } \\
\text { time }(\mathrm{h})\end{array}$ & $\begin{array}{c}\text { Temperature } \\
\left({ }^{\circ} \mathrm{C}\right)\end{array}$ & $\begin{array}{l}\text { Nitrate } \\
(\mathrm{mg} \mathrm{N} / \mathrm{l})\end{array}$ & $\begin{array}{l}\text { Conductivity } \\
(\mu \mathrm{S} / \mathrm{cm})\end{array}$ & $\mathrm{pH}$ & $\begin{array}{l}\text { Alkalinity } \\
(\mathrm{mmol} / \mathrm{l})\end{array}$ & $0-P^{a}(\mu g \mathrm{P} / \mathrm{l})$ \\
\hline (1) & 0 (Reservoir) & $7.1 \pm 0.8$ & $0.9 \pm 0.4$ & $271 \pm 6.3$ & $7.0 \pm 0.2$ & $2.7 \pm 0.0$ & $8.3 \pm 4.4$ \\
\hline (2) & 6 & $7.6 \pm 1.0$ & $0.9 \pm 0.3$ & $273 \pm 5.6$ & $7.0 \pm 0.2$ & $2.7 \pm 0.0$ & $10.7 \pm 6.4$ \\
\hline (3) & 27 & $7.2 \pm 1.4$ & $0.9 \pm 0.6$ & $273 \pm 6.4$ & $7.0 \pm 0.2$ & $2.7 \pm 0.1$ & $8.5 \pm 4.8$ \\
\hline (4) & 29 & $7.3 \pm 1.5$ & $0.9 \pm 0.4$ & $271 \pm 4.6$ & $7.0 \pm 0.2$ & $2.7 \pm 0.0$ & $8.8 \pm 4.4$ \\
\hline (5) & 44 & $7.7 \pm 1.1$ & $1.0 \pm 0.7$ & $272 \pm 6.1$ & $7.0 \pm 0.2$ & $2.7 \pm 0.1$ & $8.7 \pm 4.1$ \\
\hline (6) & 49 & $7.3 \pm 1.4$ & $0.9 \pm 0.5$ & $272 \pm 4.2$ & $7.2 \pm 0.3$ & $2.7 \pm 0.0$ & $8.9 \pm 4.7$ \\
\hline (7) & 52 & $7.6 \pm 1.1$ & $0.9 \pm 0.4$ & $273 \pm 5.0$ & $7.0 \pm 0.2$ & $2.7 \pm 0.0$ & $8.9 \pm 4.3$ \\
\hline
\end{tabular}

a o-P: orthophosphate. 
incubated at $30{ }^{\circ} \mathrm{C}$ for 7 days and then colony forming units (CFU) were counted manually. All measurements were done in triplicate.

\subsection{Assimilable organic carbon (AOC)}

A simplified version of the assimilable organic carbon (AOC) assay developed in our group (Vital et al., 2007) was used to assess regrowth potential in the water samples. Triplicate samples of each water sample were filled into sterile, carbonfree vials and incubated without any further treatment for 3 days at $30{ }^{\circ} \mathrm{C}$. Total cell concentrations of the indigenous microbial community were determined before and after incubation with flow cytometry (as described above). The netgrowth was used as indicator of the AOC concentration.

\subsection{Microbial community analysis}

\subsubsection{Denaturing gradient gel electrophoresis (DGGE)}

DNA was extracted with the DNA Water Isolation Kit (UltraClean $^{\mathrm{TM}}$ Water DNA Isolation Kit, MoBio, Carlsbad, CA, USA) following the manufacturer's instructions. Each water sample (2 l) was filtered on $0.2 \mu \mathrm{m}$ pore size filters (MoBio) and stored at $-20{ }^{\circ} \mathrm{C}$ until further processing. PCR amplification and DGGE was performed as described elsewhere (Lautenschlager et al., 2010). The $16 \mathrm{~S}$ rDNA gene was first amplified using the general bacterial primers $63 \mathrm{~F}$ and $1378 \mathrm{R}$ followed by amplification with the primers 338F-GC and 518R (Heuer et al., 1997; Muyzer et al., 1993). DGGE gel images were analyzed using the Bionumerics 5.1 software (Applied Maths, Kortrijk, Belgium). Similarities were calculated by the Pearson correlation, taking into account band intensity and band position. The clustering algorithm of unpaired pair group method (UPGMA) using arithmetic averages was used to calculate dendrograms.

\subsubsection{Pyrosequencing}

Based on the results from DGGE, one sample from each sampling location (December 2008) was further selected for $16 \mathrm{~S}$ pyrosequencing analysis together with additional water samples taken from the network at the same locations two years later (September 2010). DNA from biomass obtained on $0.2 \mu \mathrm{m}$ pore size filters was extracted using Schmidt's protocol (Schmidt et al., 1991). The 16S rRNA gene was PCR-amplified in $50 \mu \mathrm{l}$ reaction volumes in $\mathrm{S} 1000$ Thermal Cycler (BioRad, Hercules, CA, USA) using Bullseye standard Taq DNA polymerase $2.0 \times$ master mix (MIDSCI, St. Louis, MO, USA) according to the manufacturer's protocol with the following universal primers that have Roche standard barcodes 1) FA-MIDs-515F and FB909R and 2) FB-MIDs-515F and FA-909R (Tamaki et al., 2011). PCR was carried out with the following parameters: initial denaturation at $94^{\circ} \mathrm{C}$ for $3 \mathrm{~min}$, followed by 30 cycles at $94^{\circ} \mathrm{C}$ for $40 \mathrm{~s}, 56{ }^{\circ} \mathrm{C}$ for $1 \mathrm{~min}$, and $72{ }^{\circ} \mathrm{C}$ for $1 \mathrm{~min}$ with a final extension at $72{ }^{\circ} \mathrm{C}$ for $10 \mathrm{~min}$. PCR products were loaded on a $1.5 \%$ ethidium bromide stained agarose gel, ran through gel electrophoresis, and the correctly sized DNA bands were excised and purified using Wizard ${ }^{\circledR}$ SV Gel and PCR Clean-Up System (Promega, St. Louis, MO, USA) according to manufacturer's instructions. Equal amounts of purified PCR products were pooled for subsequent 454 pyrosequencing on the Titanium platform (Roche/454 Life Sciences, Switzerland) at the
W.M. Keck Center, part of the Roy J. Carver Biotechnology Center at the University of Illinois at Urbana-Champaign, USA.

\subsubsection{Data analysis}

Results of 16S rRNA gene pyrosequencing were analyzed with QIIME pipeline (Caporaso et al., 2010). Briefly, flowgrams were de-noised, and UCLUST algorithm was used for operational taxonomic units (OTU) picking. In total, the dataset contained 91414 sequences before de-noising and 90344 sequences after. A representative set of sequences that contained one sequence per unique OTU was selected. These sequences were aligned against Greengenes imputed core reference alignment using PyNAST with default settings, and chimera sequences were identified with Chimera slayer and removed. The aligned sequences were further filtered to remove gaps and non-useful information, and used to generate a phylogenetic tree for further analysis. Taxonomy assignment was conducted with RDP classifier trained by a training dataset from Greengenes OTUs at a minimum confidence level of 0.8. After taxonomy assignments, weighted and non-weighted unifrac distances were calculated and used for principal coordinates analysis (PCoA) analysis. The OTU number was also used for ordination analysis using CANOCO (Lepš and Šmilauer, 2003). The community data was first analyzed with detrended correspondence analysis (DCA) to determine suitable model to use, e.g. linear or unimodal according to the manual instructions. Following that, canonical correspondence analysis (CCA) was used for analysis for correlation between community and environmental conditions. The resulting alignment file and Greengenes' 16S rRNA gene database were input into ARB software package for phylogenetic tree construction.

\section{Results}

\subsection{Water origin, chemistry, and microbial growth potential}

The Zürich drinking water network is a complex system that is supplied with water from different treatment plants, and that includes multiple reservoirs and water pipes comprising various materials, diameters and ages (Fig. 1A). The seven sampling locations (main reservoir directly after treatment and six locations within the distribution system) were selected based on expert advice from the local water utility, taking into account the flow of water, pipe diameters in the system and the estimated average water retention times. All following data are presented according to the calculated hydraulic retention times in the system (Fig. 1B), although changes in water demand may result in variations in the $a b-$ solute values. Additionally, the origin of the water was confirmed by measurements of conductivity and water chemistry parameters (e.g., nitrate, $\mathrm{pH}$, alkalinity and phosphate) that would vary between the different water sources. All water chemistry parameters were similar at all sampling locations during the entire sampling period (Table 1). Assimilable organic carbon (AOC) concentrations were below the quantification limit $(<10 \mu \mathrm{g} / \mathrm{l})$ of the assay in all water samples and showed no significant variation during distribution (data not shown). The average TOC concentration was 
$0.88 \pm 0.03 \mathrm{mg} / \mathrm{l}$, and no detectable change in TOC was measured in samples with varied water retention times.

\subsection{Microbial abundance and activity}

The conventional cultivation-dependent HPC data were consistently below $10 \mathrm{CFU} / \mathrm{ml}$ at all sampling locations and times, and only increased slightly with water retention time (Fig. 2). In contrast, flow cytometry-based cell counts were four orders of magnitude higher than HPC-based cell counts. The treated drinking water in the reservoir contained 9.5 $( \pm 0.6) \times 10^{4}$ cells $/ \mathrm{ml}(n=6)$. This cell concentration remained constant at sampling points $2-5$, and was slightly but significantly higher at the last two sampling points (6 and 7) with average concentrations of $1.3( \pm 0.1) \times 10^{5}$ and $1.2( \pm 0.1) \times 10^{5}$ cells $/ \mathrm{ml}$, respectively $(p<0.05, n=6)$ (Fig. 2$)$. The FCM cell concentrations were remarkable stable during all four months in 2008 and also in the second sampling (two years later) with a similar trend observed between sampling points 6 and 7 and the other locations (data not shown). Microbial cell-bound ATP concentrations in the network remained stable at $1.8 \pm 1.0 \times 10^{-9} \mathrm{~g} / \mathrm{l} \mathrm{ATP}$ at sampling points 1-6 and slightly increased at sampling point 7 (52 h) (Fig. 2). The percentage of extracellular ATP was on average $42 \pm 8 \%$ of the total ATP, which emphasizes the importance of considering extracellular ATP during the analysis of drinking water samples.

\subsection{Microbial community structure and biological stability}

DGGE analysis revealed that the dominant microbial community structure after drinking water treatment remained relatively stable in the distribution network with respect to water retention time and also over the entire sampling period of four months (Fig. 3). Almost all samples taken from the reservoir and distribution network locations 2-5 showed more than $90 \%$ Pearson similarity towards each other. However, the samples derived from the two most distant sampling locations (6 and 7; Fig. 1B) clustered separately due to differences in the presence and abundance of 1-2 dominant bands (Fig. 3). Similar results on the relativeness of microbial community structure were obtained based on the PCA-based clustering analysis of the pyrosequencing data (Fig. S1). Samples 1-5 taken in 2008 were closely clustered together and were distantly away from samples 6 and 7 taken in 2008. An identical trend was observed for samples taken in 2010. However, the clustering analysis of pyrosequencing data suggested slight differences in microbial community structures between samples 1-5 taken in 2008 and 2010 (Fig. S1). Overall the change in microbial community composition in sampling points 6 and 7 coincided clearly with the small but detectable change in flow cytometry-based cell concentrations in the same samples (Fig. 2).

\subsection{Microbial diversity and composition}

Based on pyrosequencing analysis, 504 to 939 OTUs were identified in samples from the reservoir and locations in the distribution network (Fig. S2). The two locations with the lowest OTUs in both years were network sampling locations 6 and 7, with 541-632 and 504-561 OTUs, respectively (Fig. S2). This was also reflected in their lower species richness compared to the samples from other locations. OTU numbers and species estimates based on the phylogenetic metric indicated rather stable microbial diversity during the two years of sampling at all locations. Pyrosequencing results further identified 48 bacterial phyla (data not shown). The relative abundance of each phylum was determined and those present at less than $1 \%$ across all of the samples were grouped together under the "other" category. After this percentage cutoff, there were 23 bacterial phyla identified, within which

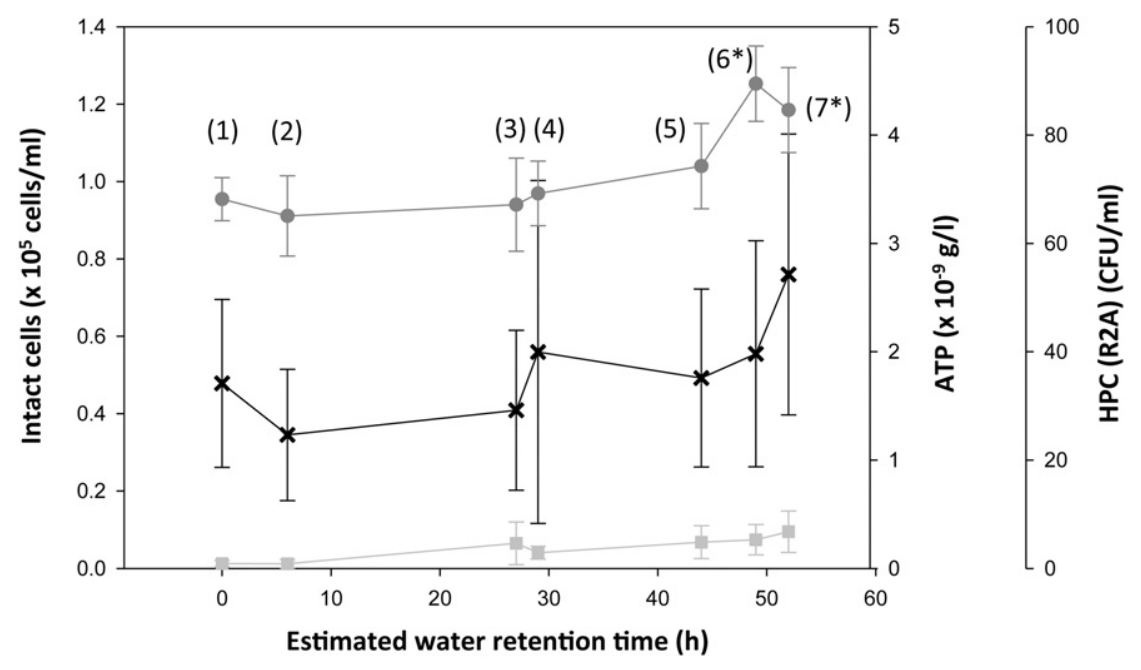

Fig. 2 - Changes in intact cells ( ), adenosine tri-phosphate (ATP) concentrations $(x)$ and heterotrophic plate counts (HPC) ( ) during drinking water distribution sorted by increasing estimated average water retention times from November 2008 until February 2009. Samples are numbered from (1)-(7) according to Table 1. Error bars indicate standard deviations from six measurements over the 4-month research period. A paired student $t$-test $\left({ }^{*} P<0.05, n=6\right)$ was used to calculate changes for each network point relative to the reservoir. 


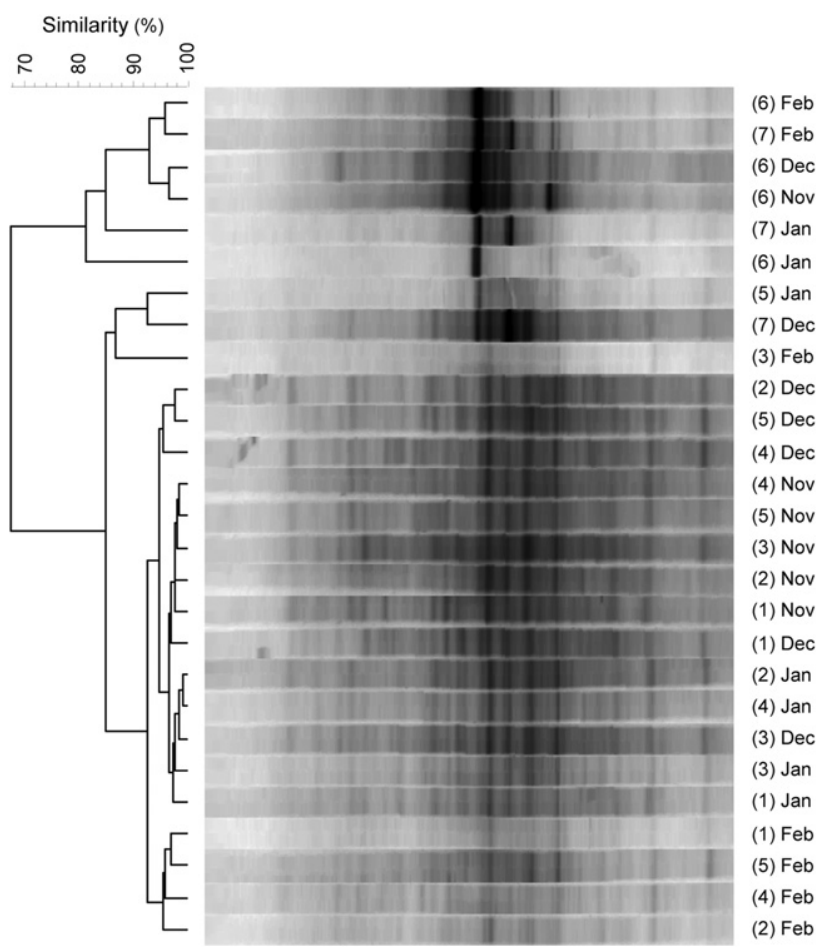

Fig. 3 - Cluster analysis of denaturing gradient gel electrophoresis (DGGE) patterns (Pearson, UPGMA) from the drinking water network. Samples are numbered from (1)-(7) according to Table 1 and the month of sampling (from November 2008 until February 2009).

approximately 10 different candidate phyla were observed at all sampling locations (Fig. 4A). Among those 23 phyla identified, the phylum Proteobacteria was the most abundant, and represented between 34 and $70 \%$ of the microbial community. Sampling points 6 and 7 had a significantly higher proportion of Proteobacteria (70\%) compared to those in the other locations (34-42\%) (Fig.4A). We further examined the distribution of OTUs found within the phylum Proteobacteria, and observed an increase in $\beta$-Proteobacteria with samples 6 and 7 (Fig. 4B). This increase was attributed to a large increase in sequences related to an unclassified Comamonadaceae. Besides Proteobacteria, 12 other known phyla were observed, and Bacteroidetes, Planctomycetes, and Elusimicrobia were relatively more abundant than the others. Their relative abundances decreased in water samples from points 6 and 7, concomitantly to the relative higher abundance of Proteobacteria, while no noticeable changes in their abundances were observed among samples taken from sampling points $1-5$ in the distribution system. Likewise, no detectable change in the abundance was observed with all the 10 candidate phyla in water samples from point 1-5, including SC3, TM7, WS3, ABY1_OD1, OP11, SM2F11, TM6, ZB2, OP3, and GN02 (Fig. 4), while a decrease in the relative abundance was observed at sampling locations 6 and 7. Their total relative abundance varied from 10 to $30 \%$. In particular, GN02 with abundance varying from 3.1\% (locations 6 and 7) to $15.6 \%$ (locations 1-5) was the most abundant candidate phylum observed. In addition to those ten candidate phyla, at least 18 minor candidate phyla (abundance $<1 \%$ ) were observed (Fig. S3). To date, very little is known about the microbial functions of most of these phyla, and their exact roles in the overall system ecology remains unclear.

\section{Discussion}

\subsection{Microbial growth potential of the water}

The term "biological stability" in essence implies that (micro) biological parameters in drinking water remain stable over time and space in a distribution network. The conventional approach to biological stability analysis throughout the last 30 years has overwhelmingly focused on assessing the microbial growth potential in water, e.g. measurements of nutrients that are used for heterotrophic growth, particularly biologically available organic carbon (Boe-Hansen et al., 2002; Block, 1992; Van der Kooij, 2003; Van der Kooij, 2000). In this respect, AOC and/or BDOC concentrations of water entering the distribution network are often used to predict the biological stability of the water (Hammes et al., 2010a; Hammes and Egli, 2005; LeChevallier et al., 1993; Van der Kooij, 2000). In the present study, all AOC data were below the quantification limit $(10 \mu \mathrm{g} / \mathrm{l})$ of the assay, while TOC data remained unchanged throughout distribution. Hence, based solely on organic carbon data, the water in the distribution network would be regarded as biologically stable. However, this assertion requires further critical evaluation: the detection/ quantification limits of both AOC and TOC analysis range between 10 and $50 \mu \mathrm{g} / \mathrm{l}$ depending on the method and sensitivity of the equipment. Previously reported yield values show that consumption of $10 \mu \mathrm{g} / \mathrm{l}$ organic carbon would result in the formation of as much as $10^{4}-10^{5}$ cells $/ \mathrm{ml}$ (Hammes et al., 2010a; Van der Kooij, 2003; Velten et al., 2011). Hence, organic carbon consumption even below the detection limit of current state-of-the-art equipment can lead to a considerable microbial growth. This suggests that measurements of organic carbon concentrations may have limited value for the assessment of biological stability in a drinking water distribution system where only small changes in nutrient concentrations and microbial growth are expected. Moreover, TOC, $\mathrm{BDOC}$, or AOC measurements would be of no value in cases where biological instability is a result of autotrophic growth, such as some denitrifying bacteria and most ammonium oxidising bacteria. Nonetheless, the present study by no means argues for the abolishment of conventional analysis of BDOC and/or AOC. In fact, AOC and/or BDOC data are still relevant parameters for the evaluation, optimisation and control of specific treatment processes, as well as for a first evaluation of water entering a distribution network. However, the present study argues strongly to complement these conventional methods with additional information on microbial parameters (e.g., FCM, ATP, community composition) during analysis of distribution networks.

\subsection{Microbial abundance and activity}

The present study explored a more direct and more sensitive approach towards the assessment of biological stability. This approach assesses and compares the multiple microbiological parameters of water samples collected from 


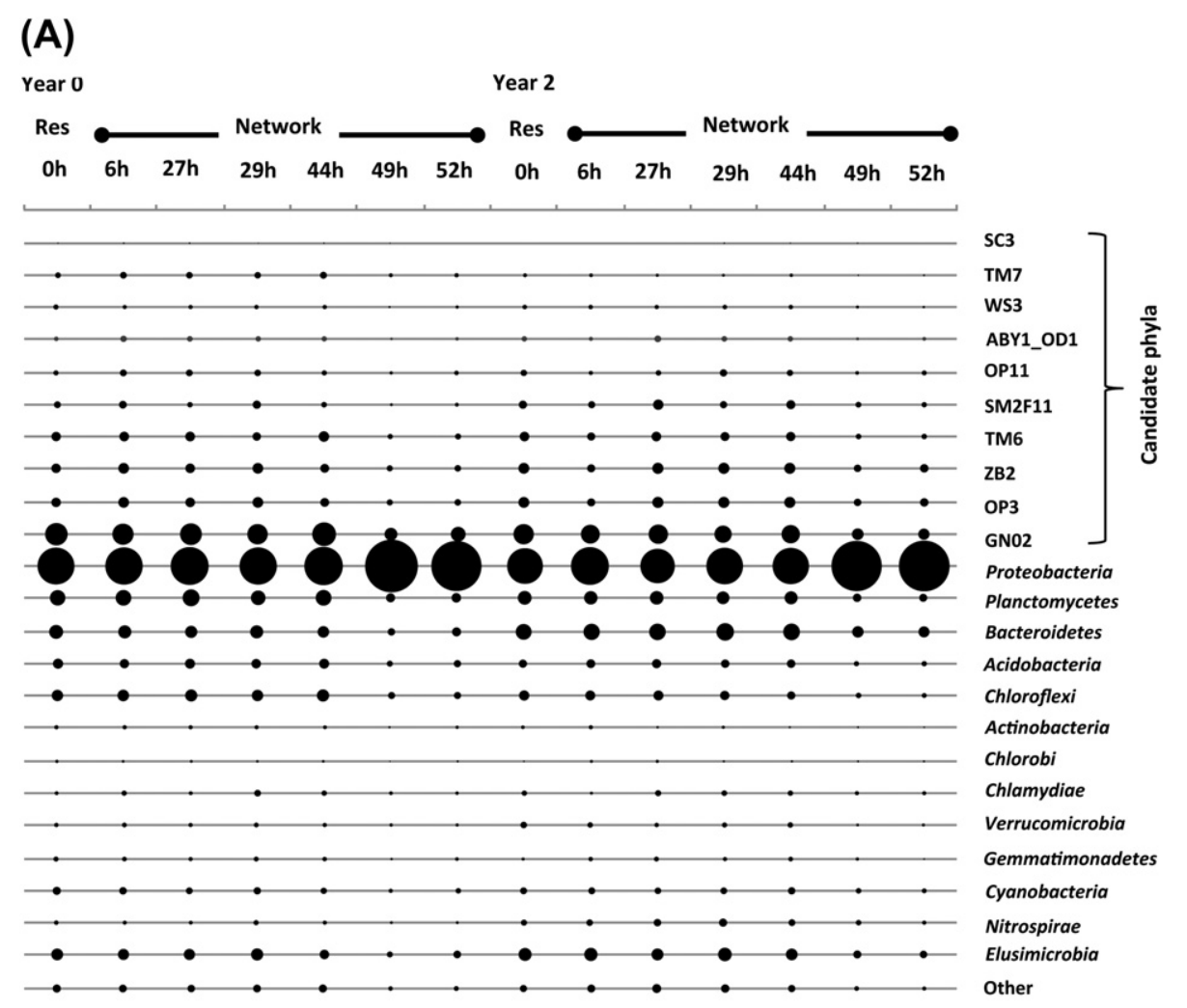

(B)

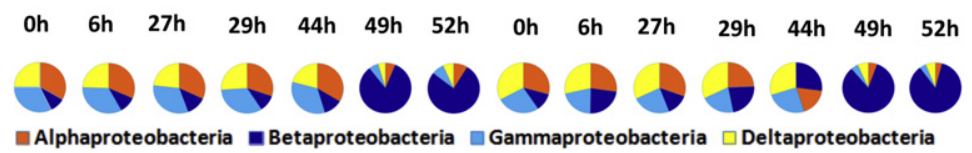

Fig. 4 - 454 pyrosequencing analysis from water samples of each sampling point in the same network from December 2008 (year 0) and September 2010 (year 2). The relative abundances of phyla (A), and Proteobacteria (B) are shown with increasing average residence time from 0 to $52 \mathrm{~h}$. Samples correlate with numbers (1)-(7) according to Table 1 and Fig. 1.

spatially/temporally-separated locations in the same network. For quantitative analysis of suspended bacterial cells, we used conventional HPC as well as FCM and ATP analysis. HPC was included because it is currently used as a routine drinking water quality parameter in most countries and this parameter is sometimes viewed as an indicator of biological stability (Carter et al., 2000; Council Directive 98/ 83EC of November, 1998; EDI, 2009; Uhl and Schaule, 2004). In the present study, the HPC numbers were constantly lower than $10 \mathrm{CFU} / \mathrm{ml}$ (Fig. 2), thus suggesting a high degree of stability in the system. However, HPC results are based on the detection of bacteria that can utilize the specific culturing media under the given cultivation conditions (Reasoner and Geldreich, 1985; Sartory 2004; Uhl and Schaule, 2004). It is well known that only a minute fraction of drinking water bacteria readily grows on conventional nutrient media (e.g. Burtscher et al., 2009; Hammes et al., 2010a; Van der Kooij, 2003). Therefore, even though the HPC data (Fig. 2) suggest a biologically stable distribution system, it may well be that growth of "uncultivable" or so-called "viable-but-not-cultivable" bacteria simply were not detected with this method.
Enumeration of the total cell concentrations (TCC) can be a good alternative to assess biological stability of drinking water, since all planktonic microbial cells can be detected and quantified, irrespective of their type or cultivability (Hammes et al., 2008, 2010a; Hoefel et al., 2005a). In a very clear example, it was previously demonstrated that microscopic total cell counts increased in parallel to decreases in BDOC concentration in an unstable distribution network (Laurent et al., 2005c). FCM analysis is sensitive enough to detect changes as low as $5 \%$ in the total cell concentration (Hammes et al., 2008), which implies that FCM should be able to correctly detect a change of $5 \times 10^{3}$ cells $/ \mathrm{ml}$ (equal to a carbon consumption as low as $0.5-5 \mu \mathrm{g} / \mathrm{l}$ ) in the water samples containing $9.5 \times 10^{4}$ cells $/ \mathrm{ml}$ as observed in the present study. Our data showed that the total cell concentrations remained remarkably stable through sampling points $1-5$ in the distribution network and over time periods of several months, largely confirming the stability described with AOC, TOC and HPC data above. However, we clearly detected a small but significant increase in cell concentrations at the two sampling points with longest average water retention times (Fig. 2), which is discussed in further detail below. 
ATP is a good indicator for viable biomass and often correlates well with flow cytometry data (Hammes et al., 2010b; Vital et al., 2012). It has been suggested as an alternative or complimentary parameter for biological stability analysis (van der Wielen and Van der Kooij, 2010; Vital et al., 2012), and used in the same context in studies on the regrowth in premise plumbing (Lautenschlager et al., 2010; Siebel et al., 2008). In the present study, the ATP concentration remained stable at sampling points $1-6$, but slightly increased at point 7 . This is not completely consistent with the FCM data and our findings suggested that the sensitivity of ATP measurements might be lower than FCM when assessing small changes in cell concentrations such as those detected in samples 6 and 7. The observed increase of $2 \times 10^{4}$ cells $/ \mathrm{ml}$ (Fig. 2) against a background of $1 \times 10^{5}$ cells $/ \mathrm{ml}$ was too close to the detection limit of the ATP method to be quantified by ATP measurements (Hammes et al., 2010b). Also, ATP concentrations can be affected by viability, activity, cell type, and cell size (Hammes et al., 2010b; Karl, 1980). Particularly small cells with low nucleic acid (LNA) content (so-called "LNA bacteria") were previously found to contain very low amounts of ATP per cell and growth of such bacteria would hardly lead to a detectable increase in ATP (Hammes et al., 2010b; Wang et al., 2009). Although conclusive evidence on the suitability of ATP to assess biological stability remains outstanding, this active biomass parameter is rather sensitive to large changes in cell concentrations opposed to small ones.

\subsection{Microbial community structure and biological stability}

In the drinking water treatment plant of Zürich, the drinking water after the final treatment step (slow sand filtration; SSF) directly enters the reservoir and then the distribution network without additional disinfection (Hammes et al., 2010a). The impact of this treatment is two-fold: firstly, the final step biofiltration seeds the drinking water with a microbial community (Fig. 2; Hammes et al., 2010a), also described recently by Pinto et al (2012). Secondly, organic carbon is removed during treatment, which should guarantee biologically stable water (Hammes et al., 2010a), while no disinfection step is used. For this reason it is anticipated that the microbial composition in the drinking water should remain the same if no regrowth had occurred. Using two different molecular techniques (DGGE and 454 pyrosequencing) in parallel to characterize the microbial communities, we observed that the major microbial populations (sequence abundance $>1 \%$ ) from the reservoir to the network points $1-5$ remained very similar, but were different from those observed at sampling points 6 and 7. This change corresponds directly to the change detected using FCM, suggesting that the two parameters have complementary value to assess biological stability. In contrast, our results based on conventional methods such as AOC, TOC, and HPC suggested no change in Zurich's drinking water distribution system. The slight difference in the microbial community composition between samples from 2008 to 2010 (measured with 454 pyrosequencing) could be either due to temporal changes in microbial community composition during the drinking water treatment process, or to slight changes in DNA quality during storage.
To our best knowledge, this is the first time the microbial community composition of non-chlorinated drinking water was studied in such detail. Similar to other drinking water systems analysed so far, Proteobacteria, which are present in most freshwater environments, dominated in the distribution networks (Burtscher et al., 2009; Eichler et al., 2006; Henne et al., 2012a; Hoefel et al., 2005a,b; Hong et al., 2010; Revetta et al., 2010; Roeder et al., 2010). However, a remarkably high abundance of candidate phyla was discovered in the present study. Candidate phyla and difficult-to-classify sequences were already observed previously in some chlorinated drinking water systems in high and low abundances (Eichler et al., 2006; Henne et al., 2012a; Hong et al., 2010; Revetta et al., 2010; Hwang et al., 2012). Nevertheless, up to now different methodologies with variations in their sensitivity have been used to study the microbial community composition of drinking water. Hence, it still needs to be elucidated in the future whether some of these candidate taxa are typical for nonchlorinated drinking water systems, or whether these were specific to the source water and treatment processes connected to this particular distribution network.

Furthermore, a high number of OTUs was observed within individual samples using the pyrosequencing technique, and a majority of these OTUs were present at low abundance $(<1 \%)$. As the result, the diversity indices (i.e., Chao1 and PD shown in Fig. S2) were relatively higher than in previous reports, where less sensitive methods such as DGGE or SSCP were used (Burtscher et al., 2009; Eichler et al., 2006), and also higher relative to the number of DGGE bands detected in this study (Fig. 3). Also, previously less microbial diversity was observed in chlorinated systems than in the non-chlorinated system here (Eichler et al., 2006; Hoefel et al., 2005a,b; Hong et al., 2010). Hence the higher diversity detected here, can be attributed to the sensitivity of the pyrosequencing technique, but possibly also to the specific environment of the Zürich drinking water distribution system, where diverse microbial populations exist in the absence of disinfectants.

Molecular analyses further revealed that the change in points 6 and 7 was due to the appearance of a dominant DGGE band, and an increase of an uncultured Commamonadacea population. Members of the Comamonadaceae group are often found in different environments including drinking water, lake water, activated sludge or soil. As they are known to utilize a large variety of substrates, it is difficult to conclude what specifically caused the increase in the Comamonadaceae population in the drinking water network (Burtscher et al., 2009; Dias and Bhat, 1964; Pernthaler et al., 1998). Furthermore, due to the complexity of the drinking water network it was not possible to elucidate the exact cause of the change. From a materials perspective, the water pipes in this network consist of steel, grey cast iron, polyethylene, cement, ductile cast iron, and ductile cast iron coated with cement mortar, differing in age. These different pipe materials were randomly distributed in the network and could not be linked to the microbiological differences observed in points 6 and 7. Making a reasonable assumption that the changes observed with FCM are the same changes observed with pyrosequencing, we could calculate that the increase in the uncultured Comamonadaceae population would be equivalent to an increase in a cell concentration of $2 \times 10^{4}$ cells $/ \mathrm{ml}$ (equal to a $20 \%$ change in 
total cell concentration). With the available information, the increases in cell concentration could best be linked to the water retention time in the network. Nevertheless, it seems unlikely, because no detectable regrowth occurred at point 5 with a hydraulic retention time of $44 \mathrm{~h}$, but at point 6 and 7 after 49 and $52 \mathrm{~h}$ retention time, respectively (Fig. 2). Alternative explanations could be localised contamination or unpredicted mixing with water from one of the other two treatment plants feeding the same network. Since the distribution system has open connections, this possibility cannot be excluded completely. However, the fact that sampling points 6 and 7 were on entirely separate water mains (Fig. 1A), renders such consistent localized contamination unlikely. Although the actual change/instability was small, it is evident that additional studies are required to elucidate the reason for the change.

\subsection{General applicability and interpretation}

The multi-parametric approach discussed herein was tested specifically on a stable non-chlorinated drinking water distribution network. However, we believe that the same approach would suffice in chlorinated systems as well. In that instance, intra-cellular ATP and intact bacterial cells (measured with FCM) would be indicative of cells surviving and (re)growing following the chlorination (Berney et al., 2008; Hammes et al., 2010b). Moreover, the use of community analysis methods to detect changes in chlorinated drinking water has been demonstrated previously (Hong et al., 2010; Hwang et al., 2012; Henne et al., 2012a), and the inclusion of an additional bacterial viability selector such as propidium mono-azide in such methods can allow even better differentiation (Nocker et al., 2010). What is not yet clear from the present data is the degree of change/instability that is acceptable before water utilities should react. Clearly, considerably more field studies on biological stability and microbial ecology from different water types, treatment and distribution systems and disinfection approaches are required to answer these questions in the future.

\section{Conclusions}

The present study demonstrated the feasibility of a multiparametric approach to assess biological stability in drinking water distribution systems. The microbial quality in a nonchlorinated drinking water distribution network was observed to remain stable over extended time periods with respect to intact bacterial cell concentrations, ATP measurements and microbial communities. A small, but measurable, change was detected at longer average retention times with FCM cell counts and community analysis, but not with conventional detection methods. So far, microbial community analysis is not typically used for the assessment of biological stability of drinking water. However, our findings suggested that molecular methods can provide in-depth information on the changes of microbial composition occurring in the system for example as a result of selective microbial growth, death or turnover of continuous attachment and detachment of bacteria to and from biofilms in drinking water distribution systems. Overall, the use of multiple tools in combination provides the opportunity to describe changes and stability during drinking water distribution in much more detail than what was previously possible.

\section{Acknowledgements}

We would like to thank Fangqiong Ling, and Hideyuki Tamaki for their help with the microbial community analysis. We are grateful to the financial support of the EU project TECHNEAU (018320).

\section{Appendix A. Supplementary data}

Supplementary data related to this article can be found at http://dx.doi.org/10.1016/j.watres.2013.03.002.

\section{R E F E R E N C E S}

Berney, M., Vital, M., Hülshoff, I., Weilenmann, H.U., Egli, T., Hammes, F., 2008. Rapid, cultivation-independent assessment of microbial viability in drinking water. Water Research 42, 4010-4018.

Block, J.C., 1992. Biofilms in drinking water distribution systems. In: Melo, L.F., Bott, T.R., Fletcher, M., Capdeville, B. (Eds.), Biofilms-Science and Technology. NATO ASI Series.

Boe-Hansen, R., Albrechtsen, H.J., Arvin, E., Jorgensen, C., 2002. Bulk water phase and biofilm growth in drinking water at low nutrient conditions. Water Research 36, 4477-4486.

Burtscher, M.M., Zibuschka, F., Mach, R.L., Lindner, G., Farnleitner, A.H., 2009. Heterotrophic plate count vs. in situ bacterial 16S rRNA gene amplicon profiles from drinking water reveal completely different communities with distinct spatial and temporal allocations in a distribution net. Water SA (Online) 35, 495-504.

Carter, J.T., Rice, E.W., Buchberger, S.G., Lee, Y., 2000. Relationships between levels of heterotrophic bacteria and water quality parameters in a drinking water distribution system. Water Research 34, 1495-1502.

Caporaso, J.G., Kuczynski, J., Stombaugh, J., Bittinger, K., Bushman, F.D., Costello, E.K., Fierer, N., Pena, A.G., Goodrich, J.K., Gordon, J.I., Huttley, G.A., Kelley, S.T., Knights, D., Koenig, J.E., Ley, R.E., Lozupone, C.A., McDonald, D., Muegge, B.D., Pirrung, M., Reeder, J., Sevinsky, J.R., Turnbaugh, P.J., Walters, W.A., Widmann, J., Yatsunenko, T., Zaneveld, J., Knight, R., 2010. QIIME allows analysis of high-throughput community sequencing data. Nature Methods 7 (5), 335-336.

Council directive 98/83/EC of November 1998: on the quality of: drinking water directive: Article 6, paragraph $1 \mathrm{a}$.

Dias, F.F., Bhat, J.V., 1964. Microbial ecology of activated sludge: I. Dominant bacteria. Applied and Environmental Microbiology $12,412$.

EDI, 2009. Hygieneverordnung des EDI (HyV) 817.024.1,23. November 2005, Stand 25. May 2009.

Eichler, S., Christen, R., Holtje, C., Westphal, P., Botel, J., Brettar, I., Mehling, A., Höfle, M.G., 2006. Composition and dynamics of bacterial communities of a drinking water supply system as assessed by RNA- and DNA-based 16S rRNA gene fingerprinting. Applied and Environmental Microbiology 72, 1858. 
Escobar, I.C., Randall, A.A., 2001. Assimilable organic carbon (AOC) and biodegradable dissolved organic carbon (BDOC) complementary measurements. Water Research 35, 4444-4454.

Hambsch, B., 1999. Distributing groundwater without a disinfectant residual. Journal of the American Water Works Association 91, 81-85.

Hammes, F., Berger, C., Köster, O., Egli, T., 2010a. Assessing biological stability of drinking water without disinfectant residuals in a full-scale water supply system. Journal of Water Supply: Research and Technology-AQUA 59, 31-40.

Hammes, F.A., Egli, T., 2005. New method for assimilable organic carbon determination using flow-cytometric enumeration and a natural microbial consortium as inoculum. Environmental Science and Technology 39, 3289-3294.

Hammes, F., Berney, M., Wang, Y., Vital, M., Köster, O., Egli, T., 2008. Flow-cytometric total bacterial cell counts as a descriptive microbiological parameter for drinking water treatment processes. Water Research 42, 269-277.

Hammes, F., Goldschmidt, F., Vital, M., Wang, Y., Egli, T., 2010 b. Measurement and interpretation of microbial adenosine triphosphate (ATP) in aquatic environments. Water Research 44, 3915-3923.

Henne, K., Kahlisch, L., Brettar, I., Höfle, M.G., 2012a. Analysis of structure and composition of bacterial core communities in mature drinking water biofilms and bulk water of a citywide network in Germany. Applied and Environmental Microbiology 78, 3530-3538.

Henne, K., Kahlisch, L., Brettar, I., Höfle, M.G., 2012b. Comparison of structure and composition of bacterial core communities in mature drinking water biofilms and bulk water of a local network. Applied and Environmental Microbiology. http:// dx.doi.org/10.1128/6373-11. Published ahead of print 2 March 2012.

Heuer, H., Krsek, M., Baker, P., Smalla, K., Wellington, E.M., 1997. Analysis of actinomycete communities by specific amplification of genes encoding 16S rRNA and gelelectrophoretic separation in denaturing gradients. Applied and Environmental Microbiology 63, 3233-3241.

Hoefel, D., Monis, P.T., Grooby, W.L., Andrews, S., Saint, C.P., 2005a. Profiling bacterial survival through a water treatment process and subsequent distribution system. Journal of Applied Microbiology 99, 175-186.

Hoefel, D., Monis, P.T., Grooby, W.L., Andrews, S., Saint, C.P., 2005b. Culture-independent techniques for rapid detection of bacteria associated with loss of chloramine residual in a drinking water system. Applied and Environmental Microbiology 71, 6479-6488.

Hong, P.Y., Hwang, C., Ling, F., Andersen, G.L., LeChevallier, M.W., Liu, W.T., 2010. Analysis of bacterial biofilm communities in water meters of a drinking water distribution system via pyrosequencing. Applied and Environmental Microbiology 76, 5631-5635.

Hwang, C., Ling, F., Andersen, G.L., LeChevallier, M.W., Liu, W.T., 2012. Microbial community dynamics of an urban drinking water distribution system subjected to phases of chloramination and chlorination treatments. Applied and Environmental Microbiology. Published ahead of print 31 Aug 2012.

Karl, D.M., 1980. Cellular nucleotide measurements and applications in microbial ecology. Microbiological Reviews 44, 739-796.

Laurent, P., Barbeau, B., Servais, P., 2005a. Evaluating the impacts of treatment modifications on regrowth potential in distribution systems: a new screening procedure using water quality modeling. Urban Water Journal 2, 81-92.

Laurent, P., Besner., M.C., Servais, P., Gauthier, V., Prévost, M., Camper, A., 2005b. Water Quality in drinking water distribution systems. In: Prévost, M., Laurent, P., Servais, P., Joret, J.C. (Eds.), Biodegradable Organic Matter in Drinking Water Treatment and Distribution. American Water Works Association, pp. 205-268. (Chapter 5).

Laurent, P., Servais, P., Gauthier, V., Prévost, M., Joret, J.C., Block, J.C., 2005c. Biodegradable organic matter and bacteria in drinking water distribution systems. In: Prévost, M., Laurent, P., Servais, P., Joret, J.C. (Eds.), Biodegradable Organic Matter in Drinking Water Treatment and Distribution. American Water Works Association, pp. 147-190. (Chapter 4).

Lautenschlager, K., Boon, N., Wang, Y., Egli, T., Hammes, F., 2010. Overnight stagnation of drinking water in household taps induces microbial growth and changes in community composition. Water Research 44, 4868-4877.

LeChevallier, M.W., Shaw, N.E., Kaplan, L.A., Bott, T.L., 1993. Development of a rapid assimilable organic carbon method for water. Applied and Environmental Microbiology 59, $1526-1531$.

Lepš, J., Šmilauer, P., 2003. Multivariate Analysis of Ecological Data Using CANOCO. Cambridge University Press, New York.

Muyzer, G., De Waal, E.C., Uitterlinden, A.G., 1993. Profiling of complex microbial populations by denaturing gradient gel electrophoresis analysis of polymerase chain reactionamplified genes coding for 16S rRNA. Applied and Environmental Microbiology 59, 695.

Nocker, A., Richter-Heitmann, T., Montijn, R., Schuren, F., Kort, S., 2010. Discrimination between live and dead cells in bacterial communities from environmental water samples analyzed by 454 pyrosequencing. International Microbiology 13, 59-65.

Pernthaler, J., Glockner, F.O., Unterholzner, S., Alfreider, A., Psenner, R., Amann, R., 1998. Seasonal community and population dynamics of pelagic bacteria and archaea in a high mountain lake. Applied and Environmental Microbiology 64, 4299-4306.

Pinto, A.J., Xi, C., Raskin, L., 2012. Bacterial community structure in the drinking water microbiome is governed by filtration processes. Environmental Science and Technology 46 (16), 8851-8859.

Reasoner, D.J., Geldreich, E.E., 1985. A new medium for the enumeration and subculture of bacteria from potable water. Applied and Environmental Microbiology 49, 1-7.

Revetta, R.P., Pemberton, A., Lamendella, R., Iker, B., Santo Domingo, J.W., 2010. Identification of bacterial populations in drinking water using $16 \mathrm{~S}$ rRNA-based sequence analyses. Water Research 44, 1353-1360.

Roeder, R.S., Heeg, K., Tarne, P., Benolken, J.K., Schaule, G., Bendinger, B., Flemming, H.C., Szewzyk, U., 2010. Influence of materials, water qualities and disinfection methods on the drinking water biofilm community. Water Practice and Technology 5.

Sartory, D.P., 2004. Heterotrophic plate count monitoring of treated drinking water in the UK: a useful operational tool* 1. International Journal of Food Microbiology 92, 297-306.

Schmidt, T.M., DeLong, E.F., Pace, N.R., 1991. Analysis of a marine picoplankton community by $16 \mathrm{~S}$ rRNA gene cloning and sequencing. Journal of Bacteriology 173, 4371-4378.

Siebel, E., Wang, Y., Egli, T., Hammes, F., 2008. Correlations between total cell concentration, total adenosine triphosphate concentration and heterotrophic plate counts during microbial monitoring of drinking water. Drinking Water Engineering and Science 1, 1-6.

SLMB, 2000. Mikrobiologie von Lebensmitteln und Futtermitteln Horizontales Verfahren für die Zählung von Mikroorganismen-Koloniezählverfahren bei 30 Grad Celcius. Schweizer Lebensmittelhandbuch.

Tamaki, H., Wright, C.L., Li, X., Lin, Q., Hwang, C., Wang, S., Thimmapuram, J., Kamagata, Y., Liu, W.T., 2011. Analysis of 16S rRNA amplicon sequencing options on the Roche/454 
next-generation Titanium sequencing platform. PloS One 6, e25263.

Uhl, W., Schaule, G., 2004. Establishment of HPC (R2A) for regrowth control in non-chlorinated distribution systems. International Journal of Food Microbiology 92, 317-325.

Van der Kooij, D., 2000. Biological stability: a multidimensional quality aspect of treated water. Water, Air, \& Soil Pollution 123, 25-34.

Van der Kooij, D., 2003. Managing regrowth in drinking- water distribution systems. In: Bartram, J. (Ed.), Heterotrophic Plate Counts and Drinking-water Safety. World Health Organization (WHO), IWA Publishing, London, UK, ISBN 1 843390256.

Van der Kooij, L., van Lieverloo, J.H.M., Schellart, J.A., Hiemstra, P., 1999. Distributing drinking water without disinfectant: highest achievement or height of folly? Aqua 48, 31-37.

Van der Kooij, D., Vrouwenvelder, J.S., Veenendaal, H.R., 2003. Elucidation and control of biofilm formation processes in water treatment and distribution using the Unified Biofilm Approach. Water Science and Technology 47, 83-90.

van der Wielen, P.W.J.J., Van der Kooij, D., 2010. Effect of water composition, distance and season on the adenosine triphosphate concentration in unchlorinated drinking water in the Netherlands. Water Research 77, 634-641.

Velten, S., Boller, M., Köster, O., Helbing, J., Weilenmann, H.-U., Hammes, F., 2011. Development of biomass in a drinking water granular active carbon (GAC) filter. Water Research 45, 6347-6354.

Vital, M., Fuchslin, H.P., Hammes, F., Egli, T., 2007. Growth of Vibrio cholerae 01 Ogawa Eltor in freshwater. Microbiology 153, 1993-2001.

Vital, M., Stucki, D., Egli, T., Hammes, F., 2010. Evaluating the growth potential of pathogenic bacteria in water. Applied and Environmental Microbiology 76, 6477.

Vital, M., Dignum, M., Magic-Knezev, A., Ross, P., Rietveld, L., Hammes, F., 2012. Flow cytometry and adenosine triphosphate analysis: alternative possibilities to evaluate major bacteriological changes in drinking water treatment and distribution systems. Water Research 46, 4665-4676.

Wang, Y., Hammes, F., Boon, N., Chami, M., Egli, T., 2009. Isolation and characterization of low nucleic acid (LNA)-content bacteria. ISME Journal 3, 889-902.

World Health Organization (WHO), 2006. Guidelines for Drinkingwater Quality: Incorporating First Addendum. In: Recommendations, third ed., vol. 1. (Geneva). 